\title{
PHOSPHONOMYCIN : ISOLATION FROM FERMENTATION SOURCES
}

\author{
Louis Ghaiet, Thomas W. Miller, Robert T. Goegelman, \\ August J. KempF and Frank J. Wolf \\ Merck Sharp and Dohme Research Laboratories \\ Rahway, N. J., U. S. A.
}

(Received for publication May 18, 1970)

\begin{abstract}
Phosphonomycin, (-)-cis-1, 2-epoxypropylphosphonic acid, was isolated from fermentation sources as a crystalline calcium salt. Methods for ionexchange adsorption, ion-exchange chromatography using both anion- and cation-exchange resins, gel-permeation chromatography, adsorption chromatography and solvent partition were investigated. The overall purification was about 5,000 fold with a yield of $12 \%$. Conditins for ion-exchange chromatography were developed based on batch equilibration studies. Thin-layer chromatography was used to develop a chromatographic procedure with alumina. The molecular weight estimated from gel-permeation studies was somewhat higher than the true value. A number of other salts which remained amorphous were also prepared.
\end{abstract}

Phosphonomycin is a new and useful antibiotic produced by a number of strains of streptomycetes ${ }^{1)}$. Early studies with fermentation broth using agar diffusion assays determined that the substance was highly polar since it was poorly adsorbed from aqueous solutions by activated carbon and could not be extracted by water

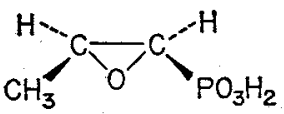
immiscible solvents. It is most stable in the $\mathrm{pH}$ range of 4 to 11 . Anionic properties were indicated by mobility toward the anode in paper electrophoresis and adsorption by anion-exchange resins at neutral $\mathrm{pH}$. Elution of the resin adsorbate with salt or solvent-salt mixtures followed by elimination of the salt by gel filtration gave concentrates of sufficient purity to demonstrate promising activity/toxicity relationships in protection of animals infected with lethal doses of various pathogenic organisms ${ }^{1,2)}$. Consequently the isolation of pure material was undertaken. This proved unusually difficult because of the low concentration of the antibiotic in the fermentation broth and the presence of impurities of similar ionic and polar properties.

Methods of purifying the crude concentrate by ion-exchange chromatography, by absorption chromatography, solvent partition and crystallization were developed. An overall purification factor of about 5,000 fold was realized by a combination of the above procedures.

Ion-exchange chromatography was studied by determining the distribution coefficient of the antibiotic in batch equilibrations at various values of $\mathrm{pH}$ and ionic strength. The data obtained were used to predict conditions useful for column 
chromatography. An approximation of the $\mathrm{pH}$ of half-ionization was obtained from chromatographic studies. Gel-filtration methods were applied for desalting ionexchange eluates and indicated a maximum molecular weight for the antibiotic in crude concentrates.

Thin-layer chromatography using a variety of adsorbent/solvent conditions was useful in determining conditions for adsorption. A chromatography procedure was devised based on these studies.

\section{Experimental Procedure}

Total Solids and Bioactivity

Dissolved solids were determined by drying an aliquot at $100^{\circ} \mathrm{C}$ and weighing the residue. The amount of antibiotic in samples was determined by disc/plate agar diffusion assays using Proteus vulgaris, MB-838, as a test organism. A crude sample was used as a working standard. The actual concentration of antibiotic in the standard solution was finally determined by comparison with pure material and the results expressed in terms of the disodium salt of phosphonomycin.

Ion-Exchange and Gel-Filtration

Columns of varying sizes were used but bed height was generally $100 \mathrm{~cm}$ or greater. Flow rates were regulated by calibrated pumps and the column effluents were monitored by a differential refractometer. For this purpose the cell of a Meeco-Matic Model II refractometer was modified for small volumes. A constant volume fraction collector was used and positive indexing with the refractometer recording assured by an event marker.

Adsorption Chromatography

Acid-washed alumina was slurried and the fines decanted several times. Bed depths of $5 \sim 30 \mathrm{~cm}$ were used and the flow rate was maintained with small liquid heads. In experiments using stepwise solvent composition changes, flow rates were maintained by pumping.

Thin-layer Chromatography

Thin-layer chromatography was carried out on $5 \times 20 \mathrm{~cm}$ plates with a $250 \mu \mathrm{m}$ layer of the desired carrier. The plates were spotted with $2 \sim 10 \mu$ l of aqueous solutions of crude phosphonomycin and developed by the ascending technique in individual chambers. After drying, the plate was placed on filter paper over the surface of agar seeded with the MB-838 organism. The agar plates were examined after 18 hours' incubation for the bioactive zone.

Evaporation and Concentration

All concentration steps were performed using high vacuum at temperatures of $35^{\circ} \mathrm{C}$ or less.

Materials

Acid-washed alumina (Merck) was used as provided. Ion-exchange resins and gel filtration materials were obtained from the manufacturer using the noted particle size.

\section{Results and Comments}

\section{Dowex $1 \times 2$ Resin Adsorption and Elution}

Harvested broth was filtered through a filter-press after the addition of filter-aid. The filtered broth contained $2.4 \mu \mathrm{g} / \mathrm{ml}$ of phosphonomycin and $13.4 \mathrm{mg} / \mathrm{ml}$ of dissolved solids. The antibiotic purity was $0.02 \%$.

Four hundred liters of filtrate adjusted to $\mathrm{pH} 7$ were adsorbed on 30 liters of Dowex $1 \times 2$ chloride cycle (50 100 mesh) resin. A resin bed depth of $75 \mathrm{~cm}$ was used and one bed volume of filtrate was passed through the resin in 10 minutes. The spent 
broth contained less than $10 \%$ of the antibiotic and was discarded. The resin adsorbate was washed with water then eluted with $3 \%$ ammonium chloride in $90 \%$ methanol and fractions of 7.5 liters were collected. Bioassays indicated that fractions 4 and 5 contained most of the activity. These were concentrated under reduced pressure to 1.4 liters. The concentrate contained $250 \mathrm{~g}$ of total solids and $0.86 \mathrm{~g}$ of phosphonomycin. This indicates a yield of $90 \%$ and a purity of $0.3 \%$. The concentrate was used for both ion-exchange and adsorption chromatography.

The antibiotic could be eluted from the resin with $3 \%$ aqueous sodium chloride but a larger eluate volume was obtained and the overall purity of salt-free product appeared similar.

Gel-Filtration

A column was prepared by soaking $2.5 \mathrm{~kg}$ of Bio-Gel P-2 (100 200 mesh) in water overnight and pouring the slurry into a glass pipe to give a bed height measuring $100 \mathrm{~cm}$. The concentrate from the previous step was adjusted to pH 5.5 and filtered, then chromatographed on the column in $275 \mathrm{ml}$ portions. The column was developed with distilled water at 50 $\mathrm{ml}$ per min. The effluent was continuously monitored with a refractometer and after discarding the first 5 liters of effluent, $22.5 \mathrm{ml}$ fractions

Fig. 1. Gel-filtration of crude phosphonomycin using 100 200 mesh Bio-Gel P-2 resin. A column $10 \times 100 \mathrm{~cm}$ containing $2.5 \mathrm{~kg}$ of resin was developed with water at $50 \mathrm{ml} / \mathrm{min}$. Concentrated ion-exchange eluate containing $49 \mathrm{~g}$ of solid in $275 \mathrm{ml}$ was charged. Total solids in effluent are indicated by refractometer tracing (solid line) and phosphonomycin by bioassay (dotted line).

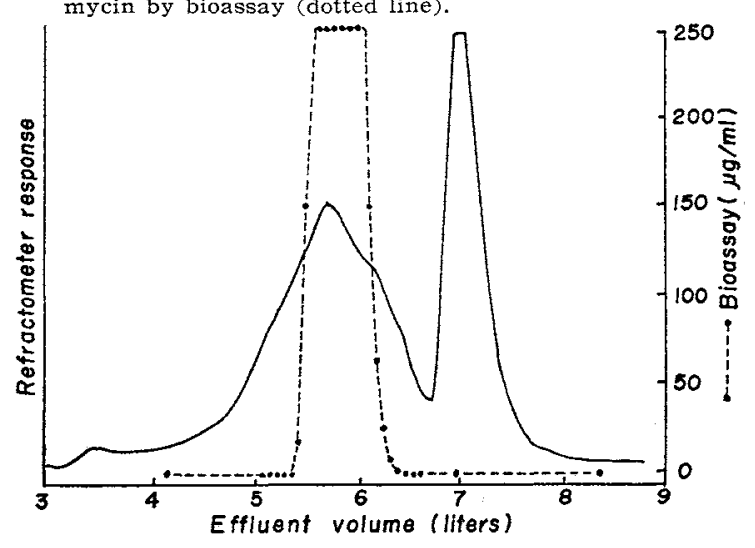
were collected automatically. The antibiotic-containing fractions were located by assay. The refractometer tracing and plotted bioassays are given in Fig. 1. Fractions 20 48, corresponding to $5,450 \sim 6,080 \mathrm{ml}$ of effluent, were combined and reassayed. A typical run gave $85 \%$ yield and $3.6 \times$ purification resulting in a sample $1 \%$ pure. The rich fractions from five runs were combined and concentrated to $660 \mathrm{ml}$ containing $66 \mathrm{~g}$ of solids.

The maximum concentration in the effluent occurred at a volume of $5,630 \mathrm{ml}$ and the void volume of the column was estimated at $3,500 \mathrm{ml}, 38 \%$ of the total column volume. These data indicate a molecular weight of 450 using published properties of the $\mathrm{gel}^{3)}$. Using the same procedure and the same column the elution volumes of sucrose and sodium chloride gave molecular weights of 220 and 100 respectively. However, when sodium acetate solution was chromatographed, the maximum concentration in the effluent occurred at a volume corresponding to a molecular weight of 350 .

Thus gel-filtration studies may be interpreted as indicating that the molecular weight of phosphonomycin is no greater than 450 and probably considerably less if the gel chromatography behavior is similar to sodium acetate.

Examination of the refractometer tracing indicates that the major purification is 
due to elimination of the salt used to elute the anion-exchange column. Thus it was considered likely that the method would not yield further significant purification of the crude concentrate.

\section{Dowex $50 \times 2$ Resin Chromatography}

A glass column, $5.3 \times 113 \mathrm{~cm}$, was filled with 2.5 liters of Dowex $50 \times 2$ hydrogen cycle resin (50 100 mesh). One hundred $\mathrm{ml}$ portions of the concentrate from the previous step were chromatographed on the column. The column was developed with distilled water using a flow rate of $19 \mathrm{ml}$ per minute. The effluent was montitored with a refractometer and 20.5 $\mathrm{ml}$ fractions were collected automatically. Fractions 45 65 were titrated to $\mathrm{pH} 7$ with $0.1 \mathrm{~N} \mathrm{NaOH}$ as they were collected. These were bioassayed and the results were plotted on the refractometer chart (Fig. 2). Fractions 52 62 corresponding to $1,050 \sim 1,290 \mathrm{ml}$ of effluent were combined and

Fig. 2. Chromatography of phosphonomycin Dowex $50 \times 2(50 \sim 100$ mesh $)$ hydrogen cycle resin developed with water. A column $5.3 \times 113 \mathrm{~cm}$ was charged with $10 \mathrm{~g}$ of solids in 100 $\mathrm{ml}$ of water. The flow rate was $19 \mathrm{ml} / \mathrm{min}$. Total solids are indicated by refractometer tracing (solid line) and phosphonomycin by bioassay (dotted line).

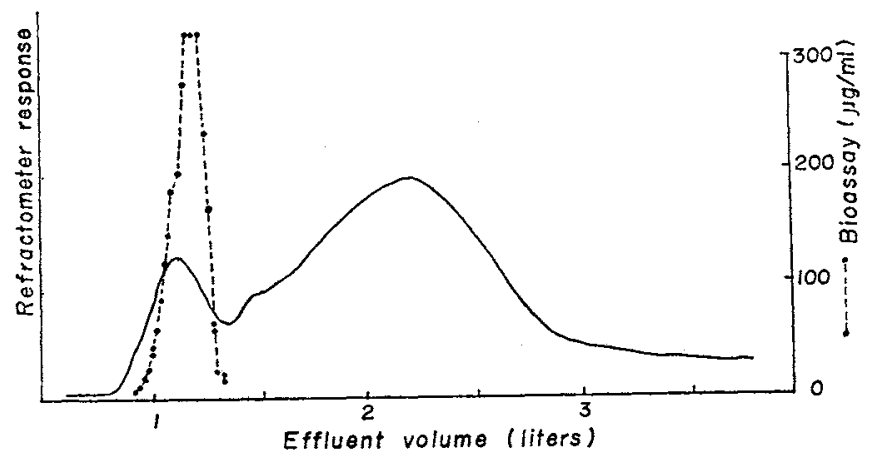
reassayed. The product from six runs was combined, concentrated and freeze-dried to yield $4.7 \mathrm{~g}$ of product of $7 \%$ purity ( $52 \%$ yield). The average equivalent weight of the eluted material appeared to be 190 based on the consumption of sodium hydroxide.

Although the antibiotic is unstable at low $\mathrm{pH}$, the exposure time in the column is relatively short and reasonable yields were usually obtained. However, samples containing mineral salts could not be chromatographed without excessive decomposition due to the low $\mathrm{pH}$ during chromatography.

The retention volume of the antibiotic was found to be slightly behind sulfuric acid and near phosphoric acid. Since sulfuric acid appears at the column void this procedure does not eliminate polar impurities. However, the refractometer chart indicates separation from appreciable quantities of less polar impurities.

The known instability of phosphonomycin at low $\mathrm{pH}$ and the limited purification obtained indicate that this method has limited utility for phosphonomycin purification. Further, since the primary degradation product is the gycol formed by opening the epoxide ring and data obtained on ion-exchange chromatography indicate the presence of a closely related compound, this step has only limited usefulness.

Distribution Coefficients with Anion-Exchange Resins

The approximate distribution coefficient of phosphonomycin between aqueous solution and anion-exchange resin was determined by batch contact of crude phosphonomycin using buffers of varying $\mathrm{pH}$ and ionic strength.

One $\mathrm{ml}$ samples of resin were equilibrated with the salt or buffer solution to be 
used and $1 \mathrm{mg}$ of crude antibiotic in $4 \mathrm{ml}$ of solution was equilibrated with the resin. The concentration of antibiotic in the aqueous phase was determined by bioassay and the concentration in the resin phase was calculated by difference. For this calculation the void volume of the resin was assumed to be $40 \%$, thus, the $5 \mathrm{ml}$ of mixture contained $0.6 \mathrm{ml}$ of resin and $4.4 \mathrm{ml}$ of solution. Distribution coefficients $\left(\mathrm{K}_{\mathrm{d}}\right)$ were calculated as concentration in resin divided by concentration in solution.

Since the accuracy of the assay is about $10 \%$, considerable variation in the calculated distribution coefficient may be obtained. Anion-exchange resins Dowex $1 \times 2$, Dowex $2 \times 4$ and Dowex 3 were studied. Data obtained with various resins in the chloride form is summarized in Fig. 3. The Rf was taken as equivalent to the fraction of phosphonomycin present in the mobile phase in any column cross section. With all three resins the predicted $\mathrm{Rf}$ in the range useful for chromatography is approximately linear with the logarithm of buffer strength at constant $\mathrm{pH}$. Of the resins tested Dowex $1 \times 2$ gave the lowest retention and would require the separation of the least amount of buffer salts. This resin was chosen for further study. $\mathrm{K}_{\mathrm{d}}$ values obtained with $0.1 \mathrm{M}$ sodium chloride, $0.1 \mathrm{M}$ sodium acetate and $0.1 \mathrm{M}$ sodium citrate at $\mathrm{pH} 5$ were nearly identical $(8.4,8.5$ and 8.5$)$ whereas with $0.1 \mathrm{M}$ sodium chloride at $\mathrm{pH} 7$ the $\mathrm{K}_{\mathrm{d}}$ value obtained was about 20 . This change is considerably less than would be expected for a single acidic function due to a normal carboxyl group with a $\mathrm{pK}$ value of about 5.5 6.5.

\section{Unbuffered Ion-Exchange Chromatography}

A column $1.4 \times 84 \mathrm{~cm}$ was filled with $130 \mathrm{ml}$ of Dowex $1 \times 2$ chloride cycle resin (50 100 mesh) and equilibrated by washing with six volumes of $0.1 \mathrm{M} \mathrm{NaCl}$. A $36 \mathrm{mg}$ sample of crude phosphonomycin from Dowex-50 chromatography was chromatographed using a flow rate of $1 \mathrm{ml} / \mathrm{min}$ of $0.1 \mathrm{M}$ sodium chloride. The effluent was monitored with a recording refractometer and $2 \mathrm{ml}$ fractions were collected automatically. The fractions were bioassayed and two active zones were detected, one with a $\mathrm{K}_{\mathrm{d}}$ value of 5 (fractions $180 \sim 268$ ) and the other with a $\mathrm{K}_{\mathrm{d}}$ value of 12 (fractions 420 $\sim 560$ ). The rich fractions from each zone were combined, concentrated to $10 \mathrm{ml}$ and desalted by chromatography on a $1.5 \times 150 \mathrm{~cm}$ column of Bio-Gel P-2 using a flow rate of $2 \mathrm{ml} / \mathrm{min}$. The bioactive fractions were combined, concentrated and freezedried. The first zone yielded $1.4 \mathrm{mg}$ of product which assayed $85 \%$ pure and the second zone yielded $3.5 \mathrm{mg}$ of product which assayed $50 \%$ pure, an overall yield of $90 \%$.

Although the dilute solutions obtained in this chromatography did not give a refractometer response, Fig. 4 gives an example of the refractometer trace and bioassay plot from an unbuffered ion-exchange chromatography column using a larger weight. of phosphonomycin. The column $(1.4 \times 82 \mathrm{~cm})$ contained $125 \mathrm{ml}$ of Dowex $1 \times 2(200 \sim$ 
$400 \mathrm{mesh}$ ) resin and was developed with $0.1 \mathrm{M} \mathrm{NaCl}$ at 1 $\mathrm{ml} / \mathrm{min}$. A $500 \mathrm{mg}$ sample of crude from Dowex $50 \times 2$ chromatography (9\% pure) was charged and $5 \mathrm{ml}$ fractions were collected. After desalting, the first peak yielded 90 mg of product $15 \%$ pure and the second, $100 \mathrm{mg}, 23 \%$ pure, a recovery of $80 \%$.

Since the products from both zones appeared to be the same antibiotic by in vitro and in vivo tests, each was rechromatographed in the same system. Each zone produced two zones. Since the feed solution was adjusted to $\mathrm{pH} 7.0$ before chromatography, this procedure separates the phosphonomycin disodium salt ( $\mathrm{K}_{\mathrm{d}}$ about 12) from the less strongly adsorbed monosodium salt.

Assuming that there was no redistribution of available cations with the impurities present during the chromatography, the ratio of monosodium to disodium phosphonomycin at $\mathrm{pH} 7$ is about 0.4 . This corresponds to a $\mathrm{pK}$ value of about 6.6 for the second acidic function of phosphonomycin. This value agrees with that observed by titration of pure phosphonomycin, pK 6.4.

Examination of Fig. 4 shows the presence of an impurity with very similar retention to the antibiotic. The impurity occurs with both peaks and therefore has been ascribed to the presence of 1,2-dihydroxypropylphosphonic acid formed by opening of the epoxide ring of phosphonomycin.

\section{Buffered Ion-Exchange Chromatography}

Since the presence of two peaks was undesirable, it was necessary to properly buffer the ion-exchange chromatography. However, the buffers commonly used in the $\mathrm{pH}$ range of $5 \sim 7$ could not be separated from the product by gel-filtration. Pyridine hydrochloride was used instead. A $4.7 \times 145 \mathrm{~cm}$ (2.5 liter) column of Dowex $1 \times 2$ chloride cycle resin $(200 \sim 400 \mathrm{mesh})$ was equilibrated with $0.05 \mathrm{M}$ pyridine hydrochloride adjusted to $\mathrm{pH}$ 5.0 , then $12.7 \mathrm{~g}$ of crude antibiotic $(5.5 \%$ pure) in $30 \mathrm{ml}$ of buffer was applied. The chromatography was carried out at a flow rate of $10 \mathrm{ml}$ per minute.

Fig. 5. Buffered chromatography on Dowex $1 \times 2$ (200 400 mesh) with pH 5.0, $0.05 \mathrm{M}$ pyridine tydrochloride.

A $444 \mathrm{mg}$ sample of $5 \%$ purity was charged to a $1.4 \times 82 \mathrm{~cm}$ column and developed at $1 \mathrm{ml} / \mathrm{min}$ Total solids are indicated by refractometer tracing (solid line) and phosphonomycin by bioassay (dotted line)

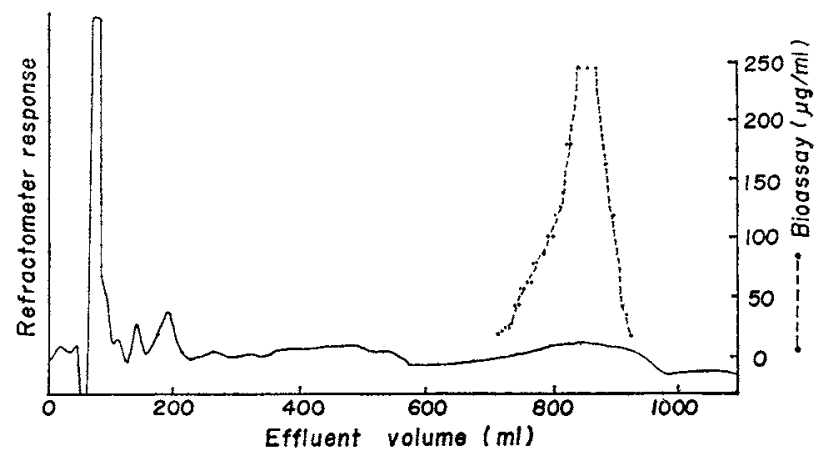


After 11.7 liters of effluent was discarded, $25 \mathrm{ml}$ fractions were collected automatically. The fractions were bioassayed and only one band was detected having a $K_{d}$ value of 11 (fractions $129 \sim 315$ ). The rich fractions were pooled, adjusted to $\mathrm{pH} 8.2$ with sodium hydroxide and concentrated to remove pyridine. The concentrate $(30 \mathrm{ml})$ was desalted on a $5.3 \times 103 \mathrm{~cm}$ column of Bio-Gel P-2 using a flow rate of $20 \mathrm{ml} / \mathrm{min}$. The bioactive fractions were combined, concentrated and freeze-dried to yield $887 \mathrm{mg}$ of essentially pure antibiotic. No improvement in potency was obtained on rechromatography.

An example of the refractometer tracing and bioassay plot from a buffered ionexchange chromatography column is given in Fig. 5 . The column $(1.4 \times 82 \mathrm{~cm})$ contained $125 \mathrm{ml}$ Dowex $1 \times 2(200 \sim 400 \mathrm{mesh})$ resin and was developed with $0.05 \mathrm{M}$ pH 5.0 buffer at $1 \mathrm{ml} / \mathrm{min}$. A $444 \mathrm{mg}$ sample of crude phosphonomycin, $5 \%$ pure, was charged and $5 \mathrm{ml}$ fractions were collected. The yield after removal of the buffer was $62 \mathrm{mg}$ of $33 \%$ pure antibiotic, a recovery of $90 \%$. The reference compartment of the refractometer cell was filled with buffer. The break in the refractometer trace is caused by the water used to dissolve the sample and marks the void volume of the column. The first large peak is caused by buffer displaced from the resin by adsorption of the sample itself.

Examination of refractometer and bioassay recordings from the ion-exchange chromatography (Fig. 4 and Fig. 5) indicates that the method can be used only with those lots of material which do not have appreciable quantities of the closely related impurity with very similar properties. Separation from this impurity is incomplete. Thus, although the method was helpful it could not be used with confidence with all lots of phosphonomycin.

\section{Thin-Layer Chromatography}

Thin-layer chromatography was investigated as a method of determining possible adsorbent-solvent combinations which could be used for purification of the crude concentrate. With silica-gel G plates, no movement of the antibiotic (detected by bioautograph) was obtained with methanol, isopropanol-water $(7: 3)$ or methanolwater $(1: 1)$. Water alone gave a streak as did a buffered mixture of butanol and pyridine with water. However, slight mobility was observed with the system ethanol water-conc. ammonia (25:3:4).

Using acid washed alumina plates, no mobility was observed with water or methanol-water mixtures. However, aqueous ammonia and diethylamine gave an $\mathrm{Rf}$ of nearly 1 . These few trials indicated the possible application of alumina in the purification of phosphonomycin.

\section{Primary Alumina Purification}

Forty $\mathrm{kg}$ of acid washed alumina was slurried in water and poured onto a 28inch filter-pot to create an alumina bed $10 \mathrm{~cm}$ deep. Sixty liters of Dowex $1 \times 2$ resin eluate concentrate (from sodium chloride elution) containing $27.2 \mathrm{~kg}$ of solids and $21.9 \mathrm{~g}$ of phosphonomycin was adjusted to $\mathrm{pH} 5.7$ and filtered through the alumina under gentle vacuum at a rate of about $500 \mathrm{ml}$ per minute. The alumina adsorbate was washed on the filter-pot with 20 liters of water, 40 liters of $75 \%$ methanol-water and 80 liters of $75 \%$ methanol made $1 \mathrm{M}$ with concentrated ammonia water. The 
Table 1. Isolation of phosphonomycin-Primary alumina treatment

\begin{tabular}{l|c|c|c|c}
\hline & $\begin{array}{c}\text { Volume } \\
(\text { liter })\end{array}$ & Solids $(\mathrm{g})$ & $\begin{array}{c}\text { Phosphonomycin } \\
(\mathrm{g})\end{array}$ & Purity (\%) \\
\hline Dowex $1 \times 2$ resin eluate concentrate & 60.0 & 27,240 & 21.6 & 0.08 \\
Alumina spent effluent & 132.0 & 24,440 & 0.8 & 0.003 \\
$75 \% \mathrm{MeOH}-1 \mathrm{M} \mathrm{NH}_{3}$ wash & 75.0 & 714 & 0 & - \\
Aqueous-1 $\mathrm{M} \mathrm{NH}_{3}$ concentrate & 7.0 & 700 & 20.9 & 3.0 \\
\hline
\end{tabular}

antibiotic was eluted from the alumina with 120 liters of $1 \mathrm{M}$ aqueous ammonia. The eluate was evaporated to 7 liters. The concentrate contained $20.9 \mathrm{~g}$ of phosphonomycin and $700 \mathrm{~g}$ of solids. Total solids and assays on the fractions are shown in Table 1.

The primary alumina purification procedure was considerably easier to manipulate than the gel filtration step and yielded a product about one half as pure as that obtained from the Dowex 50 chromatography procedure. When combined with the ion-exchange treatment of broth, the two steps are capable of reducing the volume from broth about 700 fold. The yield is good and the procedure is readily operated on any scale.

Alumina Chromatography-Methanol Gradient

Since ammonia in the presence of $75 \%$ methanol did not elute phosphonomycin from alumina, an attempt was made to upgrade the purity of the antibiotic by alumina chromatography using a step-wise methanol gradient. Two $100 \mathrm{~g}$ alumina chromatograms were run with $75 \%, 50 \%, 25 \%$ and $0 \%$ methanol elution in which each solution was made $2 \mathrm{~N}$ with ammonia. The first chromatogram had a high ratio of feed solids to alumina whereas the second chromatogram had as its feed a low solids ratio obtained from a rich fraction of the first chromatogram.

The feed for the first chromatogram was obtained by processing a Dowex $1 \times 2$ resin eluate through batchwise adsorption on alumina and elution with ammonia. The evaporated eluate was treated with 9 volumes of methanol and filtered to yield a filtrate (2 liters) containing $34 \mathrm{~g}$ of solids and $293 \mathrm{mg}$ of phosphonomycin. The methanol solution was passed through a $2.5 \times 20 \mathrm{~cm}$ column of alumina at a rate of $2 \mathrm{ml}$ per minute and the column was washed with $100 \mathrm{ml}$ of $90 \%$ methanol. The alumina was eluted stepwise with $400 \mathrm{ml}$ portions of $75 \%, 50$ $\%, 25 \%$ and $0 \%$ methanol, each solution being $2 \mathrm{~N}$ ammonia. One hundred $\mathrm{ml}$ fractions were collected and assayed. The results shown in Table 2 indicate an 87 $\%$ recovery of phosphonomycin and a $103 \%$ recovery of solids. The phosphonomycin rich fractions from the $50 \%$ and $25 \%$ methanol eluates were combined, evaporated, and 9 volumes of methanol added. The filtrate contained phosphonomycin at a

Table 2. Methanol gradient-2 $\mathrm{N}$ ammonia elution of phosphonomycin from a $100 \mathrm{~g}$ alumina column (high loading)

\begin{tabular}{|c|c|c|c|c|}
\hline & $\begin{array}{l}\text { Volume } \\
(\mathrm{ml})\end{array}$ & $\begin{array}{l}\text { Solids } \\
\text { (g) }\end{array}$ & $\begin{array}{l}\text { Phosphono- } \\
\text { mycin (mg) }\end{array}$ & $\begin{array}{c}\text { Purity } \\
(\%)\end{array}$ \\
\hline Feed $-90 \% \mathrm{MeOH}$ & 2,000 & 34.0 & 293 & 0.86 \\
\hline Spent effuent & 2,060 & 19.4 & 0 & - \\
\hline $75 \% \mathrm{MeOH}-2 \mathrm{~N} \mathrm{NH}_{3}$ & 400 & 7.8 & 0 & - \\
\hline $50 \% \mathrm{MeOH}-2 \mathrm{~N} \mathrm{NH}_{3}$ & $\begin{array}{l}100 \\
100 \\
100 \\
100\end{array}$ & $\begin{array}{l}1.4 \\
3.2 \\
1.1 \\
0.5\end{array}$ & $\begin{array}{r}3.9 \\
61.5 \\
25.0 \\
22.2\end{array}$ & $\begin{array}{l}0.28 \\
1.92 \\
2.27 \\
4.45\end{array}$ \\
\hline $25 \% \mathrm{MeOH}-2 \mathrm{~N} \mathrm{NH}_{3}$ & $\begin{array}{l}100 \\
100 \\
100 \\
100\end{array}$ & $\begin{array}{l}0.54 \\
0.55 \\
0.34 \\
0.20\end{array}$ & $\begin{array}{r}33.4 \\
75.0 \\
26.0 \\
5.9\end{array}$ & $\begin{array}{r}6.20 \\
13.60 \\
7.70 \\
2.94\end{array}$ \\
\hline Aqueous $2 \mathrm{~N} \mathrm{NH}_{3}$ & $\begin{array}{l}100 \\
100 \\
100 \\
100\end{array}$ & $\begin{array}{l}0.02 \\
0.03 \\
0.03 \\
0.02\end{array}$ & $\begin{array}{l}0.5 \\
0.25 \\
0.15 \\
0 .\end{array}$ & $\begin{array}{l}2.5 \\
0.8 \\
0.5\end{array}$ \\
\hline Material balance & & $\begin{array}{l}35.1 \\
(103 \%)\end{array}$ & $\begin{array}{c}253.8 \\
(87 \%)\end{array}$ & \\
\hline
\end{tabular}


purity of $7.6 \%$.

Five hundred $\mathrm{ml}$ of methanol filtrate from the first chromatogram containing $1.38 \mathrm{~g}$ of solids was chromatographed on $100 \mathrm{~g}$ of alumina as above. The results are shown in Table 3. Whereas much of the phosphonomycin was eluted with $50 \%$ methanol in the first chromatogram with a high loading of solids, none of the antibiotic was eluted from alumina
Table 3. Methanol gradient-2 $\mathrm{N}$ ammonia elution of phosphonomycin from a $100 \mathrm{~g}$ alumina column (low loading)

\begin{tabular}{l|c|c|c|c}
\hline & $\begin{array}{c}\text { Volume } \\
(\mathrm{ml})\end{array}$ & $\begin{array}{c}\text { Solids } \\
(\mathrm{g})\end{array}$ & $\begin{array}{c}\text { Phosphono- } \\
\text { mycin (m) }\end{array}$ & $\begin{array}{c}\text { Purity } \\
(\%)\end{array}$ \\
\hline Feed-90\% MeOH & 510 & 1.38 & 104.0 & 7.6 \\
Spent effluent & 600 & 0.18 & 0 & - \\
$75 \% \mathrm{MeOH}-2 \mathrm{~N} \mathrm{NH}_{3}$ & 400 & 1.03 & 0 & - \\
$50 \% \mathrm{MeOH}-2 \mathrm{~N} \mathrm{NH}_{3}$ & 400 & 3.50 & 0 & - \\
$25 \% \mathrm{MeOH}-2 \mathrm{~N} \mathrm{NH}_{3}$ & 100 & 0.34 & 0 & - \\
& 100 & 0.41 & 0 & - \\
& 100 & 0.18 & 33.3 & 18.5 \\
Aqueous 2 N NH & 100 & 0.09 & 19.3 & 21.5 \\
& 100 & 0.06 & 7.4 & 12.3 \\
& 100 & 0.24 & 5.6 & 2.3 \\
\hline Material balance & & 6.03 & 65.6 & \\
\hline
\end{tabular}
in $50 \%$ methanol with a low solids loading. The amount of solids obtained was more than four times that in the feed with a $63 \%$ yield of phosphonomycin. Although a purity of over $20 \%$ was obtained in one fraction, the leaching of solids from alumina into methanol-ammonia obscured the true picture of the phosphonomycin purity. Because of the ambiguity of the antibiotic purity and the effort required for large scale chromatography, the methanol gradient elution was abandoned in favor of solvent partition of the concentrate obtained by the primary purification procedure.

\section{Solvent Partition}

The phosphonomycin concentrate (7 liters) obtained from the primary alumina purification was added to ten volumes (70 liters) of methanol with agitation. The methanol insoluble material was filtered and discarded. Three volumes of $n$-butanol (231 liters) were added to the methanol filtrate with agitation. The mixture was filtered and the insoluble material discarded. The methanol-butanol filtrate (308 liters) was evaporated under vacuum at a temperature below $35^{\circ} \mathrm{C}$ to one-half volume (154 liters). The butanol insoluble material was filtered and discarded. The butanol solution was saturated with water and extracted twice with 0.1 volume of water. The water extracts were combined, adjusted to $\mathrm{pH} 7$ with ammonia and evaporated to 2 liters. The solution contained $10.7 \mathrm{~g}$ of phosphonomycin and $35 \mathrm{~g}$ of total solids.

The solvent partition method was found useful in elimination of more polar compounds, probably glycol, from phosphonomycin concentrates. Since phosphonomycin is also highly polar, large quantities of solvent were required and the overall yield is only about $50 \%$. The antibiotic recovery over the methanol treatment is generally quantitative but with the addition of butanol some phosphonomycin is precipitated along with impurities. Additional antibiotic is precipitated on concentration of the butanol solution. The extraction of the antibiotic into water is highly efficient with a reduction of ten fold in volume. A second water extract is used to remove residual antibiotic from the butanol. The low $\mathrm{pH}$ of the water extracts indicates that phosphonomycin in the partial acid form is taken into the butanol since the butanol insoluble solids have a $\mathrm{pH}$ of 6.5. However, lowering the $\mathrm{pH}$ of the concentrate prior to solvent treatment did not appear to increase the yield of phosphonomycin in the butanol soluble fraction. 
Final Purification

Five hundred grams of alumina were slurried in water and poured into a $13 \mathrm{~cm}$ sintered glass funnel to give a bed height of about $4 \mathrm{~cm}$. A one liter portion of the water extract concentrate obtained above was adjusted to $\mathrm{pH} 5.7$ with dilute hydrochloric acid and passed through the alumina bed at a rate of $5 \mathrm{ml} / \mathrm{min}$. The alumina was washed with $500 \mathrm{ml}$ of water and eluted with 2 liters of $1 \mathrm{~N}$ ammonia water collecting $200 \mathrm{ml}$ fractions. Fractions 2 through 5 containing about $60 \%$ of the antibiotic were combined and evaporated to $65 \mathrm{ml}$. This eluate concentrate was subjected to the same solvent treatment with methanol and $n$-butanol as described above. The first water exTable. 4. Final purification of phosphonomycin

\begin{tabular}{|c|c|c|c|c|}
\hline & $\begin{array}{c}\text { Volume } \\
(\mathrm{ml})\end{array}$ & $\begin{array}{l}\text { Solids } \\
\text { (g) }\end{array}$ & $\begin{array}{l}\text { Phosphono- } \\
\text { mycin (g) }\end{array}$ & $\begin{array}{c}\text { Purity } \\
(\%)\end{array}$ \\
\hline Alumina feed & 1,000 & 17.5 & 5.35 & 30 \\
\hline Alumina spent & 1,700 & 18.0 & 0 & - \\
\hline $\begin{array}{ll}\text { Ammonia eluates } & 1 \\
& 2 \sim 5 \\
& 6 \sim 10\end{array}$ & $\begin{array}{r}200 \\
800 \\
1,000\end{array}$ & $\begin{array}{l}9.3 \\
6.4 \\
1.5\end{array}$ & $\begin{array}{l}2.0 \\
2.9 \\
0.3\end{array}$ & $\begin{array}{l}22 \\
45 \\
20\end{array}$ \\
\hline Methanol soluble & 720 & 5.4 & 2.8 & 52 \\
\hline Methanol-butanol soluble & 2,800 & 2.9 & 2.4 & 83 \\
\hline Anhydrous butanol soluble & 1,000 & $1.4^{*}$ & 1.5 & 90 \\
\hline Water extract $\frac{1}{2}$ & $\begin{array}{l}100 \\
100\end{array}$ & $\begin{array}{l}1.2^{*} \\
0.2^{*}\end{array}$ & $\begin{array}{l}1.3 \\
0.25\end{array}$ & $\begin{array}{l}90 \\
90\end{array}$ \\
\hline
\end{tabular}

* Phosphonomycin present as mono-ammonium salt. tract had a $\mathrm{pH}$ of 3.4 and had a solids content of $2 \mathrm{mg} / \mathrm{ml}$. The combined extracts contained $1.4 \mathrm{~g}$ of essentially pure antibiotic as the ammonium salt (Table 4).

Salts of Phosphonomycin

The sodium, potassium, lithium, barium, magnesium and calcium salts of phosphonomycin were prepared by the addition of their respective hydroxides to the antibiotic rich extract until a $\mathrm{pH}$ of 9.5 was reached. The respective solutions were then evaporated to about one-half volume to remove ammonia and any insoluble material was discarded. The filtrates had a pH of 7.0 7.5. Each salt was obtained as a solid product by lyophilization.

\section{Crystallization of Calcium Salt}

To $100 \mathrm{ml}$ of phosphonomycin final water extract containing $1.2 \mathrm{~g}$ of pure antibiotic, calcium hydroxide powder $(640 \mathrm{mg})$ was added with agitation until $\mathrm{pH} 9.5$ was reached. The mixture was evaporated to $60 \mathrm{ml}(\mathrm{pH} \mathrm{7.4)}$ and filtered. The filtrate was further evaporated to $40 \mathrm{ml}$ and crystals appeared. The crystalline slurry was stirred for about 2 hours and the crystals were filtered and washed with water. The product was dried to constant weight in vacuo and weighed $700 \mathrm{mg}$. The mother liquor was agitated overnight and a second crop of crystals was filtered, washed with water and dried to yield $341 \mathrm{mg}$ of product.

\section{Properties of Phosphonomycin Calcium Salt}

The crystalline calcium salt does not melt up to a temperature of $250^{\circ} \mathrm{C}$. The solubility in water appears to be about $7 \mathrm{mg} / \mathrm{ml}$ at room temperature. The elemental analysis is as follows: C $20.4 \%, \mathrm{H} 3.4 \%, \mathrm{P} 16.7 \%, \mathrm{Ca} 20.5 \%, \mathrm{O}$ (diff) $39 \%$. The weight loss at high temperature (above $200^{\circ} \mathrm{G}$ ) in vacuo was $9.1 \%$. These data are consistent with an elemental composition of $\mathrm{C}_{3} \mathrm{H}_{5} \mathrm{O}_{4} \mathrm{PCa} \cdot \mathrm{H}_{2} \mathrm{O}$ (Calculated $\mathrm{C} 18.55 \%$, $\mathrm{H} 3.64 \%, \mathrm{P} 15.95 \%$, Ca $20.6 \%, \mathrm{O} 42.2 \%$ ). The specific rotation was found to be $[\alpha]_{\mathrm{D}} 3.8$ (c 0.7 , water). 


\section{Summary of Isolation Process}

The most successful process for the isolation of phosphonomycin from broth is summarized in Table 5 . The combination of six steps gives an overall purification from the starting material of about 5,000 fold in about $12 \%$ yield. The major yield losses were encountered in the final steps and reflect the difficulty of separation of phosphonomycin from the closely related

Table 5. Isolation of phosphonomycin

\begin{tabular}{l|c|c|c}
\hline & $\begin{array}{c}\text { Volume } \\
\text { (liter) }\end{array}$ & $\begin{array}{c}\text { Purification } \\
\text { factor }\end{array}$ & $\begin{array}{c}\text { Phosphono- } \\
\text { mycin (g) }\end{array}$ \\
\hline Filtered broth & 1,000 & - & 2.4 \\
Anion-exchange eluate & 37 & $15 \times$ & 2.2 \\
Alumina purification & 0.7 & $10 \times$ & 2.1 \\
$n$-Butanol soluble in $\mathrm{H}_{2} \mathrm{O}$ & 0.2 & $10 \times$ & 1.1 \\
Alumina chromatography & 0.1 & $1.5 \times$ & 0.6 \\
n-Butanol soluble in $\mathrm{H}_{2} \mathrm{O}$ & 0.025 & $2.0 \times$ & 0.3 \\
Crystallization & 0.01 & $1.1 \times$ & 0.3 \\
\hline Total volume reduction & $10^{5}$ & Purification & Yield $12 \%$ \\
\hline
\end{tabular}
impurities.

\section{Discussion}

Although each of the isolation methods given above was useful in the studies which culminated in the determination of the chemical structure of phosphonomycin, no step could be considered as completely satisfactory and each possessed difficulties which seemed inherent in the method. No method was obtained with high selectivity for the antibiotic in the presence of closely related polar impurities.

Ion-exchange or adsorption on alumina were the only two methods capable of substantially reducing the volume and solids from the starting broths. Scale-up of gel filtration desalting of the ion-exchange eluate was a major problem and desalting by alumina adsorption was more convenient. The apparent exclusion of either sodium acetate or sodium phosphonomycin by Bio-Gel P-2 resin illustrates a major pitfall in the use of this method for the determination of the molecular size of highly charged substances at least in the absence of a background electrolyte. Since elimination of salt was the major objective, the effect of added electrolytes on the retention volume was not studied nor were other gel permeation materials investigated. Although the exclusion properties contributed to increased separation from the eluting salt of the ion-exchange step, lack of separation from other simple organic ions probably contributed to the limited purification obtained.

The use of ion-exchange resins as partitioning agents rather than as ion-exchange agents has been reported for the separation of neutral compounds on either anion or cation-exchange resins ${ }^{4)}$ and the fractionation of the free base forms of aminoglycoside antibiotics on strong base anion-exchange resins has been previouly reported ${ }^{5}$. The partitioning of acidic materials on sulfonic ion-exchange resins ${ }^{6)}$ has been described.

With Dowex $50 \times 12$ polar, strongly acidic acids are less retarded than weaker acids. The observed retention for phosphonomycin is thus an indication of the strongly acidic polar nature of the compound and provides a convenient method for its separation from less polar weaker acids. Unfortunately, phosphonomycin is not stable as the free acid and although the chromatography may be carried out rapidly, any glycol formed is very difficult to remove in subsequent steps. The free acid product from the chromatography is desirable because it can be converted to any salt of the antibiotic.

The adsorption of phosphonomycin by surface-active adsorbents again reflects the highly polar nature of the antibiotic in that practically no adsorption occurs on activated carbon whereas the polar adsorbents, silica gel and alumina, show very high affinity for the antibiotic. Because of the poor mechanical characteristics of silica in aqueous systems, alumina was used for chromatographic experiments. 
Although the mechanism of the adsorption was not investigated, the adsorbed species appears to be singly charged. At $\mathrm{pH}$ values which produce the doubly charged species, the adsorption is very weak. Since acid washed alumina usually retains anions, it is not clear whether the adsorption is of the classical surface interaction type or whether ion-exchange properties are important. Either mechanism or a combination of the two would result in the observed adsorption-elution behavior. The slow dissolution of the alumina under eluting conditions obscures the purification obtained by this method. However, the gradient procedure when used with a reasonable solids to alumina ratio appears to give substantial purification and it is possible that further refinements in this method would lead to a good fractionation procedure.

As it became clear that one of the major contaminants was a highly polar substance, methods of separation based on polarity were undertaken. The solvent partition step described above did eliminate, by virtue of insolubility, more polar contaminants. Although heroic quantities of solvent were used to solubilize the phosphonomycin a substantial loss was obtained. Solvents more polar than butanol could probably have been substituted but this aspect was not studied further.

\section{Acknowledgement}

The authors are grateful to E. HeNDrzak and W. R. Knellwitz for laboratory assistance and to W. M. MAIESE for assistance in agar diffusion assays. Large scale operations were supervised by $D$. W. KRECH and W. L. SUBJaCK.

\section{References}

1) Hendlin, D.; E. O. Stapley, M. Jackson, H. Wallick, A. K. Millea, F. J. Wolf, T. W. Miller, L. Chaiet, F. Kahan, E. L. Fortz, H. B. Woodruff, J. M. Mata, S. Hernandez \& S. Mochales : Phosphonomycin: A new antibiotic produced by strains of Streptomyces. Science $166: 122,1969$

2) Christensen, B. G.; W. J. Leanza, T. R. Beatrie, A. A. Patchett, B. H. Arison, R. E. Ormond, F. A. Kuehl, Jr., G. Albers-Schonberg \& O. Jardetzky : Phosphonomycin: Structure and synthesis. Science $166: 123,1969$

3) Bio-Rad Laboratories, Price List S. Feb. 1, 1967

4) Samuleson, O. \& B. Swenson: Particification chromatography on ion-exchange resins separation of sugars. Anal. Chim. Acta $28: 426 \sim 432,1963$

5) Rothrock, J. W.; R. T. Goegelman \& F. J. Wolf: A resin chromatographic analysis for kanamycin mixture. Antibiot. Ann. 1958/1959:796 803, 1959

MAEHR, H. \& C. P. SCHAFFnER : The separation and differentiation of the gentamicin complex. J. Chromatography $30: 572 \sim 578,1967$

6) Harlow, G. A. \& D. H. Morman : Automatic ion exclusion-partition chromatography. Anal. Chem. $36: 2438 \sim 2442,1964$ 